\title{
The Role of Insulin, IGF-1 and PRAS40 in the Processes of Oncogenesis in Women with Type 2 Diabetes Mellitus and Endometrial Cancer
}

\author{
Tamara Vatseba
}

\begin{abstract}
The objective of the research was to investigate the content of insulin, insulin-like growth factor-1 and phosphorylated protein kinase proline-rich Akt substrate of $40 \mathrm{kDa}$ and to determine their role in the activation of oncogenesis processes in women with type 2 diabetes mellitus and endometrial cancer.

Materials and methods. There were examined 46 women who were divided into 4 groups: Group I included healthy women; Group II comprised women with type 2 diabetes mellitus; Group III included women with endometrial cancer; Group IV comprised women with endometrial cancer and co-existent type 2 diabetes mellitus. The levels of insulin, insulin-like growth factor-1, phosphoproline-rich Akt substrate of 40kDa were determined by immune-enzyme analysis. The compensation of diabetes mellitus was evaluated by hemoglobin A1c level using method of ion-exchange chromatography. The results obtained were analyzed using statistical analysis.

Results. Women of all study groups had increased levels of insulin and insulin-like growth factor-1 as compared to the control group $(p<0.05)$. The level of phospho-proline-rich Akt substrate of $40 \mathrm{kDa}$ increased in the patients of Group II $(p<0.05)$ and the patients of Group III $(p<0.05)$ and decreased in the patients of Group IV $(p<0.05)$. According to correlation analysis, phospho-proline-rich Akt substrate of $40 \mathrm{kDa}$ was found to correlate with body mass index, insulin and insulin-like growth factor-1 in Group II, body mass index and insulin-like growth factor-1 in Group III and body mass index in Group IV $(p<0.05)$.

Conclusions. There was found an association between type 2 diabetes mellitus and endometrial cancer through obesity, hyperinsulinemia and insulin-like growth factor-1. The increase in phospho- proline-rich Akt substrate of $40 \mathrm{kDa}$ level was a sign of activation of mTOR and oncogenesis processes in the patients with type 2 diabetes mellitus. The decrease in phospho-proline-rich Akt substrate of $40 \mathrm{kDa}$ in the patients with endometrial cancer and co-existent type 2 diabetes mellitus can be explained by the influence of other intracellular regulatory systems or the effects of antidiabetic drugs, that requires additional study.
\end{abstract}

\section{Keywords}

diabetes mellitus; cancer risk; endometrial cancer; signaling pathways

Ivano-Frankivsk National Medical University, Ivano-Frankivsk, Ukraine

Corresponding author: tamara.vatseba@gmail.com

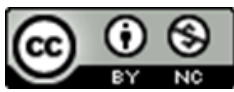

Copyright (C)Tamara Vatseba, 2019

\section{Problem statement and analysis of the latest research}

According to the recent research, there is an increased risk of cancer in the patients with diabetes mellitus (DM), including pancreatic, liver, intestine, breast, urinary tract and endometrial cancers [11, 16]. Data on prostate cancer are ambiguous [15]. Endometrial cancer (EC) is one of the most common cancer localizations in women during menopause. There are two types of EC: the first type (estrogen-dependent) is associated with the effect 


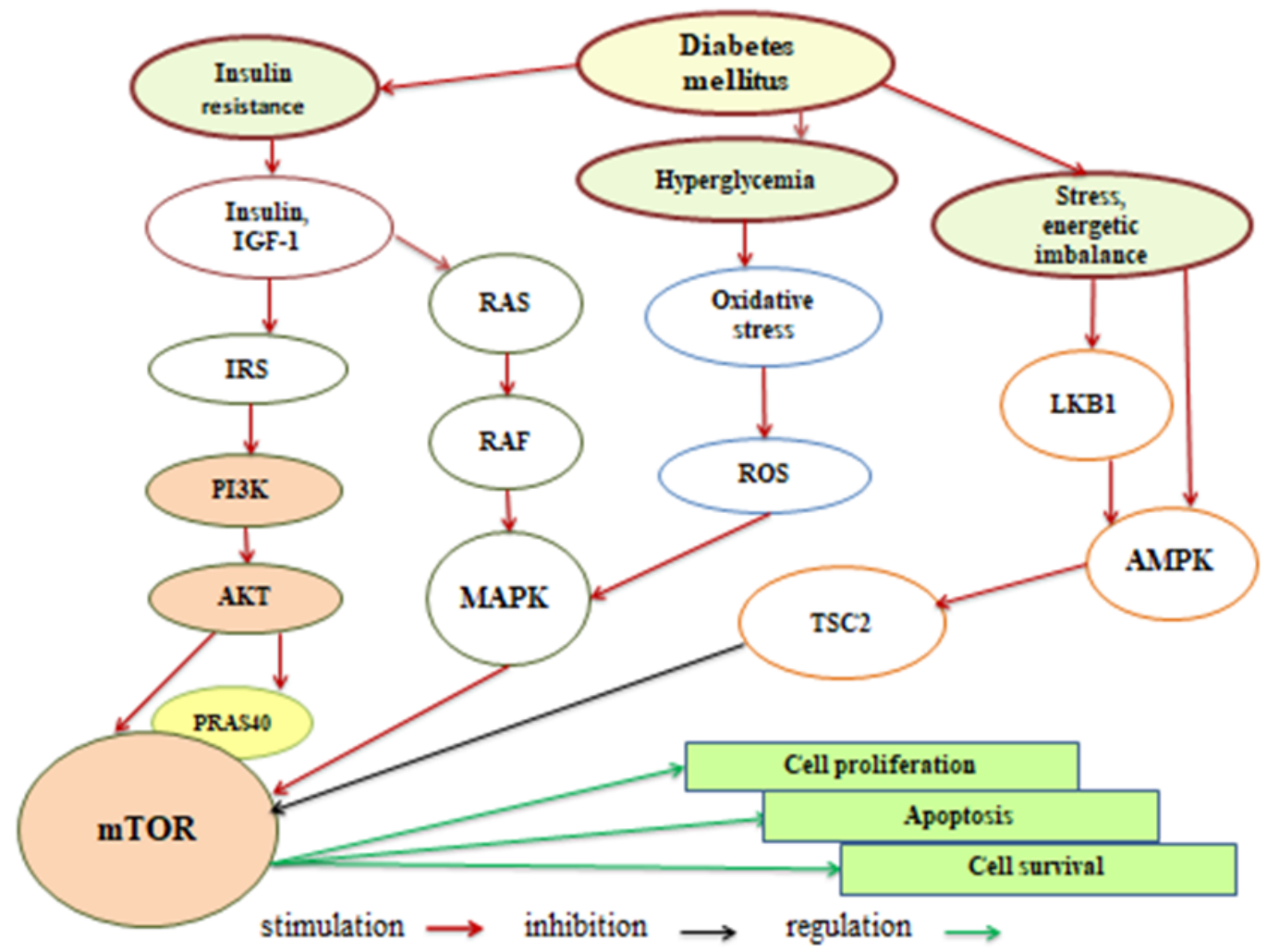

Figure 1. Mechanisms of activation of oncogenesis in patients with T2DM: IGF-1 - insulin-like growth factor-1; Akt - alpha serine/threonine-protein kinase B; RAS - membrane-bound proteins, which are involved in signal transduction; RAF - proteins, components of MAPK kinase; ROS - reactive oxygen species; LKB1 - liver kinase B1; AMPK - adenosine monophosphate-activated protein kinase; TSC2 tuberous sclerosis complex 2 .

of hyperestrogenemia in women with endocrine and metabolic disorders (obesity, DM, hypertension) and is observed in $70 \%$ of cases, while the second type, autonomous (non-estrogen-dependent), is found in less than $30 \%$ of the patients, occuring on the background of endometrial atrophy in case of the absence of hyperestrogenism and metabolic disorders.

The common pathogenetic mechanisms of developing type $2 \mathrm{DM}$ (T2DM) and reproductive cancer are obesity, chronic inflammation and cytokine imbalance, hyperinsulinemia and insulin resistance (IR), hyperglycemia and oxidative stress (OS) [12]. These factors cause pathological changes at the intracellular level, thereby initiating the processes of proliferation and inhibition of apoptosis [5].

Hyperinsulinemia and high levels of IGF activate tyrosine kinase of the insulin receptor substrate
(IRS), leading to signal transduction via the intracellular signaling pathways: the RAS/RAF/ mitogenactivated protein kinase (MAPK) and phosphatidylinositol 3-kinase (PI3K) /Akt/mTOR (Fig. 1).

$\mathrm{PI} 3 \mathrm{~K} / \mathrm{Akt} / \mathrm{mTOR}$ is one of many signaling pathways that are typical for most human cells. It mediates the main effects of insulin in cells, namely stimulates the synthesis of protein, glycogen, lipids, suppresses gluconeogenesis, lipolysis, and regulates key aspects of cancer, including cell growth and survival. Being influenced by insulin, PI3K activates the serine/threonine protein kinase cascade, which includes phosphoinositide-dependent kinase-1 (PDK-1), the substrate of which is the Akt of the protein kinase B family. Akt is a key enzyme for signal trasmission along this path; moreover, it is involved in the regulation of glycemia level by influencing glycogen synthesis and translo- 


\section{The Role of Insulin, IGF-1 and PRAS40 in the Processes of Oncogenesis in Women with Type 2 \\ Diabetes Mellitus and Endometrial Cancer - 3/6}

cation of the main glucose transporter - glucose transporter type 4 (GLUT-4). In many malignant diseases, Akt acts as oncogene due to the phosphorylation of substrates, including the mammalian target of rapamycin (mTOR) [8]. mTOR includes two complexes: mTOR complex 1 (mTORC1) and mTOR complex 2 (mTORC2). Raptor and prolinerich Akt substrate of 40kDa (PRAS40) are specific for mTORC1, while Rictor, mitogen-activated protein kinase-associated protein 1 (mSin1) and Protor$1 / 2$ are specific for mTORC2. These complexes interact with different substrates and initiate different signaling paths. The mTOR regulates the processes of apoptosis, cell proliferation and cell survival (Fig. 1).

PRAS40 is a substrate of Akt-1 (Akt1S) in the signaling cascade $\mathrm{PI} 3 \mathrm{~K} / \mathrm{Akt} / \mathrm{mTORC} 1$. It is part of mTORC1 and is its negative regulator. Phosphorylation of PRAS40 leads to the dissociation of PRAS40 from Raptor in the mTOR complex that facilitates the activation of mTOR. PRAS40 and mTOR are involved in regulating cell sensitivity to insulin. Increased level of phospho-PRAS40 was found identified in several types of tumors, including endometrial, cervical and ovarian ones. Thus, this protein kinase can serve as a potential target during the treatment of various types of cancer [17].

The pathogenetic factors of DM contribute to the dysfunction of intracellular regulatory systems, namely the PI3K/Akt/mTOR signaling pathway, which is now considered as one of the therapeutic goals of molecular-directed cancer treatment [1].

The objective of the research was to investigate the content of insulin, IGF-1 and phosphoPRAS40 and to determine their role in the activation of oncogenesis processes in women with T2DM and EC.

\section{Materials and Methods}

There were examined 46 women. All the patients were divided into 4 groups: Group I included healthy women; Group II comprised women with T2DM; Group III included women with EC; Group IV comprised women with EC and co-existent T2DM. The groups of patients were homogeneous by age, and severity of the disease. Antidiabetic therapy (ADT) for the patients with DM included various combinations of tablets and insulin. All the patients signed an informed consent for further diagnostic and research work. The content of phosphoPRAS40, levels of insulin and IGF-1 were determined by immune-enzyme assay using diagnostic reagents human PRAS40 [pT246], Enzyme Linked Immunosorbent Assay (ELISA) kit KHO0421 (Invitrogen, USA), Insulin ELISA EIA-2935 (DRG, Germany) and IGF-1 600 ELISA EIA-4140 (DRG, Germany). Hemoglobin A1c (HbA1c) was determined by ion exchange chromatography, using diagnostic reagents Bio-Rad (USA).

The analysis of the data was carried out using Statistica 12.0 (StatSoft Inc., USA), One-Way ANOVA program. The data are presented as $\mathrm{x} \pm \mathrm{SD}$ ( $\mathrm{x} \pm$ standard deviation). The differences between the values in the control and experimental groups were determined using the Student's t-test. The values of $\mathrm{p}<0.05$ were considered as significant.

\section{Results and Discussion}

The analysis of the anthropometric data indicated the tendency of women with EC to obesity; BMI was $>30 \mathrm{~kg} / \mathrm{m}^{2}$. Age-related characteristics confirmed the prevalence of EC in women in the postmenopausal period. HbA1c levels in Group II and Group IV were higher than $8.0 \%$, indicating DM decompensation. Hyperinsulinemia was found in the patients with DM of both groups $(\mathrm{p}<0.05)$ and in women of Group III $(\mathrm{p}<0.05)$. Significantly higher level of IGF-1, as compared to the control group, was found in the patients of all groups $(\mathrm{p}<0.05)$. Significantly higher content of phosphoPRAS40 was detected in Group II and Group III $(\mathrm{p}<0.05)$, while in Group IV, it decreased significantly $(\mathrm{p}<0.05)$ (Table 1$)$.

The elevated insulin levels in all study groups confirmed insulin resistance in the patients with T2DM, as well as in the patients with obesity. Excessive synthesis of insulin decreased the production of IGF-binding proteins 1, 2 (IGFBP1, 2) in the liver and promoted IGF bioavailability.

In addition, hyperinsulinemia led to decrease 
Table 1. Levels of insulin, IGF-1, phospho-PRAS40 in the patients with T2DM and EC.

\begin{tabular}{|c|c|c|c|c|}
\hline Indicator & $\begin{array}{l}\text { Group I } \\
\text { (the control } \\
\text { group), } \\
\mathrm{n}=10\end{array}$ & $\begin{array}{l}\text { Group II, } \\
\text { DM type } 2 \text {, } \\
\text { n=12 }\end{array}$ & $\begin{array}{c}\text { Group III, } \\
\text { EC, } \\
\mathrm{n}=12\end{array}$ & $\begin{array}{c}\text { Group IV, } \\
\text { DM type } 2+E C, \\
n=12\end{array}$ \\
\hline Age, (years) & $58.91 \pm 8.96$ & $55.23 \pm 6.19$ & $62.25 \pm 2.45$ & $61.58 \pm 6.91$ \\
\hline BMI, $\left(\mathrm{kg} / \mathrm{m}^{2}\right)$ & $29.17 \pm 3.75$ & $32.10 \pm 3.68$ & $33.86 \pm 3.70$ & $31.84 \pm 6.19$ \\
\hline Insulin, (mIU/ml) & $7.1 \pm 2.4$ & $27.2 \pm 11.1^{*}$ & $11.8 \pm 2.1 * / * *$ & $17.5 \pm 11.7 * / * *$ \\
\hline IGF-1, (ng/ml) & $141.3 \pm 28.9$ & $177.9 \pm 29.9 * / \#$ & $481.9 \pm 292.4 *$ & $183.3 \pm 37.7 * / \#$ \\
\hline ph-PRAS40, U/ml & $1.148 \pm 0.101$ & $1.744 \pm 0.459 *$ & $1.809 \pm 0.591 *$ & $0.131 \pm 0.014 *$ \\
\hline
\end{tabular}

in the synthesis of sex hormone-binding globulin (SHBG) in the liver, thereby increasing the levels of free estrogen. SHBG has been identified as an indicator of an increased risk of EC [9, 12].

The elevated level of IGF-1 in Group III indicated the additional mechanisms for stimulating its synthesis during EC, not only by hyperinsulinemia. The increase in the level of this growth hormone may be due to the effects of obesity and cytokine imbalance. The obesity impact on the risk of reproductive cancer is caused by active conversion of androgens to estradiol in peripheral adipose tissue, as well as through the state of chronic inflammation and cytokine imbalance. Proinflammatory cytokines (interleukin-6 (IL-6) and tumor necrosis factor- $\alpha(\mathrm{TNF}-\alpha))$ have pro-cancerogenic effects in case of the excess, activating the PI3K/Akt/mTOR signaling pathway of cell proliferation. Overexpression of leptin in cancerous ovarian tissues is recognized as the marker of aggressive malignancy. In contrast, adiponectin (APN) has a direct inhibitory effect on tumor cells [10, 14].

Hyperestrogenic effects can be involved in this type of cancer, since estradiol stimulates local synthesis of IGF in endometrial tissue [10, 14].

The reduced level of IGF-1 in the patients of Group II and Group IV with T2DM in comparison with those in Group III may be attributed to the positive pleiotropic effects of metformin, which was used in the treatment of most patients; that co- incided with the results of other scientific studies on the ability of this drug to affect pathogenetic "diabetes-induced" mechanisms of cancer, including the level of IGF-1 $[2,4]$. Other research explained the increase in IGF-1 levels through insulin resistance in the patients with T2DM and the binding of IGF-2 to IGF-1 receptor [7]. The study carried out by Dai $\mathrm{C}$ et al., did not show a significant difference between the levels of IGF-1 in the patients who had both T2DM and EC and in those, who had EC only. However, there was detected the activation of receptors to IGF-2 in endometrial cancer cells, which explains the activation of PI3K due to the loss of competitive binding of IGF-2 to receptors of IGF-1 [6].

The increase in the content of phospho-PRAS40 in the patients of Group II and Group III indicated the activation of the PI3K/Akt/mTOR signaling pathway through the pathogenetic mechanisms of cancer and T2DM, including obesity, hyperinsulinism and increase in IGF-1 level.

The decrease in phospho-PRAS40 level in women with EC secondary to T2DM can be explained by the influence of other intracellular regulators, namely the activation of AMPK. A co-existence of DM and cancer associated with severe chronic stress, energy deficit, activating the tumor suppressor LKB1 and AMPK, promotes the phosphorylation of TSC2 that leads to suppressing the mTOR signaling pathway $[3,13]$. On the other hand, the decreased level 


\section{The Role of Insulin, IGF-1 and PRAS40 in the Processes of Oncogenesis in Women with Type 2 \\ Diabetes Mellitus and Endometrial Cancer - 5/6}

of phospho-PRAS40 may be explained by the influence of ADT or due to the competition of protein kinases of various signaling pathways for common substrates, which requires additional study.

In women of Group II with T2DM, phosphoPRAS40 correlated with BMI $(\mathrm{r}=0.57, \mathrm{p}<0.05)$, insulin $(\mathrm{r}=0.56, \mathrm{p}<0.05)$ and IGF-1 $(\mathrm{r}=0.48, \mathrm{p}<0.05)$. In women of Group III, phospho-PRAS40 correlated with BMI $(\mathrm{r}=0.42, \mathrm{p}<0.05)$ and IGF-1 $(\mathrm{r}=0.45$, $\mathrm{p}<0.05)$. In women of Group IV, phospho-PRAS40 correlated with BMI $(r=0.50, \mathrm{p}<0.05)$ only.

The dependence of phospho-PRAS40 content on the level of insulin and IGF-1 in the patients with T2DM proved the important influence of these growth factors on the oncogenesis processes. No significant effect of hyperglycemia on the activity of phospho-PRAS40 was detected. However, most patients of Group IV had decompensated diabetes, which certainly contributes to carcinogenesis. Chronic hyperglycemia and pathological pathways of glucose transformation lead to OS, the accumulation of ROS, which contributes to the oxidation of intracellular structures (proteins, lipids, DNA) and causes their mutations and dysfunction. OS activates the ROS/MAPK signaling pathway, that controls gene transcription, metabolism, as well as proliferation, apoptosis and cell survival (Fig. 1).

The determination of the level of phosphoPRAS40 provides an opportunity to evaluate the activity of the PI3K/Akt/mTOR signaling pathway in the patients with T2DM and cancer. For a practicing endocrinologist, the relevance of achieving DM compensation, correcting hyperinsulinemia and normalizing IGF-1 level in order to prevent the dysregulation of intracellular systems being involved in processes of carcinogenesis are confirmed

\section{Conclusions}

There was found an association between T2DM and EC through obesity, hyperinsulinemia and activation of IGF-1. The increase in the level of phosphoPRAS40 was a sign of activating mTOR and oncogenesis processes in the patients with T2DM. The decrease in phospho-PRAS40 in the patients with EC and co-existent T2DM can be explained by the influence of other intracellular regulatory systems or the effects of antidiabetic drugs, that requires additional study.

\section{References}

[1] Andersen JN, Sathyanarayanan S, Di Bacco $A$ et al. Pathway-based identification of biomarkers for targeted therapeutics: personalized oncology with PI3K pathway inhibitors. Sci Transl Med. 2010;2(43):43ra55. DOI: https://doi.org/10. $1126 /$ scitranslmed. 3001065

[PMid:20686178]

[2] Anisimov VN, Bartke A. The key role of growth hormone-insulin-IGF1 signaling in aging and cancer. Crit Rev Oncol Hematol. 2013;87(3):20123. DOI: https://doi.org/10. $1016 / j . c r i t r e v o n c .2013 .01 .005$ [PMid:23434537 PMCid:PMC4095988]

[3] Carling D. AMPK signalling in health and disease. Curr Opin Cell Biol. 2017;45:3137. DOI: https://doi.org/10.1016/ j.ceb.2017.01.005 [PMid:28232179]

[4] Chae YK, Arya A, Malecek MK et al. Repurposing metformin for cancer treatment: current clinical studies. Oncotarget. 2016;7(26):4076740780. DOI: https://doi.org/10. 18632 / oncotarget. 8194

[5] Chen L, Chen R, Wang H et al. Mechanisms linking inflammation to insulin resistance. Int $\mathrm{J}$ Endocrinol. 2015;2015:508409. DOI: https : //doi.org/10.1155/2015/508409 [PMid:26136779 PMCid:PMC4468292]

[6] Dai C, Li N, Song G et al. Insulin-like growth factor 1 regulates growth of endometrial carcinoma through PI3k signaling pathway in insulin-resistant type 2 diabetes. American Journal of Translational Research. 2016;8(8):3329-3336. 
[7] Emons G, Beckmann MW, Schmidt D et al. Uterus commission of the Gynecological Oncology Working Group (AGO). New WHO Classification of Endometrial Hyperplasias. Geburtshilfe Frauenheilkd. 2015;75(2):135136. DOI: https://doi.org/10.1055/ s-0034-1396256 [PMid:25797956 PMCid:PMC4361167]

[8] Farese RV, Sajan MP. Metabolic functions of atypical protein kinase C: "good" and "bad" as defined by nutritional status. Am J Physiol Endocrinol Metab. 2010;298(3):385394. DOI: https://doi .org/10.1152/ ajpendo.00608.2009 [PMid:19996389 PMCid:PMC3774273]

[9] Gallagher EJ, Le Roith D. Diabetes, cancer, and metformin: connections of metabolism and cell proliferation. Ann N Y Acad Sci. 2011;1243:5468. DOI: https://doi.org/10. $1111 / j .1749-6632.2011 .06285 . x$ [PMid:22211893]

[10] García-Jiménez C, Gutiérrez-Salmerón M, Chocarro-Calvo A et al. From obesity to diabetes and cancer: epidemiological links and role of therapies. $\mathrm{Br} \mathrm{J}$ Cancer. 2016;114(7):716-722. DOI: https: //doi.org/10.1038/bjc.2016.37

[PMid:26908326 PMCid:PMC4984860]

[11] Harding JL, Shaw JE, Peeters A et al. Cancer risk among people with type 1 and type 2 diabetes: disentangling true associations, detection bias, and reverse causation. Diabetes Care. 2015;38(2):264270. DOI: https://doi.org/10.2337/ dc14-1996 [PMid:25488912]

[12] Hendriks SH, Schrijnders D, van Hateren KJ et al. Association between body mass index and obesity-related cancer risk in men and women with type 2 diabetes in primary care in the Netherlands: a cohort study (ZODIAC-56). BMJ Open. 2018 ;8(1):e018859. DOI: https://doi.org/
$10.1136 / \mathrm{bmjopen}-2017-018859$

[PMid:29371278 PMCid:PMC5786141]

[13] Howell JJ, Hellberg K, Turner $M$ et al. Metformin inhibits hepatic mTORC1 signaling via dose-dependent mechanisms involving AMPK and the TSC complex. Cell Metab. 2017;25(2):463-471. DOI: https://doi. org/10.1016/j.cmet.2016.12.009

[PMid:28089566 PMCid:PMC5299044]

[14] Hua F, Yu JJ, Hu ZW. Diabetes and cancer, common threads and missing links. Cancer Lett. 2016;374(1):54-61. DOI: https://doi.org/10.1016/j. canlet.2016.02.006 [PMid:26879686]

[15] Jian Gang P, Mo L, Lu Y, Runqi L et al. Diabetes mellitus and the risk of prostate cancer: an update and cumulative metaanalysis. Endocr Res. 2015;40(1):5461. DOI: https://doi.org/10. 3109/07435800.2014.934961

[PMid:25105463]

[16] Vatseba TS, Sokolova LK. Breast cancer in women with diabetes mellitus type 2 . World of Medicine and Biology. 2019;2(68):30-34. DOI: https://doi.org/10.26724/ 2079-8334-2019-2-68-30-34

[17] Wang H, Zhang Q, Wen Q et al. Proline-rich Akt substrate of 40kDa (PRAS40): a novel downstream target of PI3k/Akt signaling pathway. Cell Signal. 2012;24(1):1724. DOI: https://doi.org/10. 1016/j.cellsig.2011.08.010

[PMid:21906675]

Received: 2019-08-31

Revised: 2019-11-06

Accepted: 2019-11-09 